\title{
DEMENTIA AND MILD COGNITIVE IMPAIRMENT IN PATIENTS WITH PARKINSON'S DISEASE
}

\author{
Gloria Maria Almeida Souza Tedrus', Lineu Corrêa Fonseca', Grace Helena Letro', \\ Alexandre Souza Bossoni $i^{3}$ Adriana Bastos Samara ${ }^{4}$
}

\begin{abstract}
The objective of this research was to assess the occurrence of cognitive impairment in 32 individuals (average age: 67.2 years old) with Parkinson's disease (PD). Procedures: clinical-neurological assessment; modified Hoehn and Yahr staging scale (HYS); standard neuropsychological battery of CERAD (Consortium to Establish a Registry for Alzheimer's Disease); Pfeffer questionnaire; and Clinical Dementia Rating. A comparison was made with a control group (CG), consisting of 26 individuals with similar age and educational level but without cognitive impairment. The PD patients showed an inferior performance in the CERAD battery when compared to the CG. Three PD sub-groups were characterised according to cognition: no cognitive impairment - 15 cases; mild cognitive impairment - 10; dementia - 7 cases. There was a significant association between motor disability (HYS) and the occurrence of dementia. Dementia and mild cognitive impairment frequently occur in PD patients and should be investigated in a routine way.
\end{abstract}

KEY WORDS: Parkinson disease, dementia, cognition.

\section{Demência e transtorno cognitivo leve em pacientes com doença de Parkinson}

Resumo - O objetivo desta pesquisa foi avaliar a ocorrência de déficits cognitivos em 32 indivíduos (idade média: 67,2 anos) com doença de Parkinson (DP). Procedimentos: avaliação clínico-neurológica, escala de Hoehn and Yahr modificada (EHY), bateria neurospicológica do CERAD (Consortium to Establish a Registry for Alzheimer's Disease), questionário de Pfeffer e escore clínico da demência (Clinical Dementia Rating). Foi feita comparação com grupo controle (GC) de 26 indivíduos sem declínio cognitivo, com idade e nível educacional similares. Os pacientes com DP tiveram desempenho inferior na bateria CERAD, quando comparados ao do GC. Foram caracterizados 3 subgrupos com PD segundo a cognição: sem déficits cognitivos - 15 casos; transtorno cognitivo leve - 10; demência - 7 casos. Houve associação entre comprometimento motor e ocorrência de demência. Demência e transtorno cognitivo leve são freqüentes em pacientes com DP e devem ser investigados de modo rotineiro.

PALAVRAS-CHAVE: doença de Parkinson, cognição, demência.

Parkinson's disease (PD) was initially characterised as a movement disorder with preservation of the intellectual abilities, but recently dementia has been shown in from 10 to $95 \%$ of PD patients, depending on the population studied and the diagnostic criteria and methods used ${ }^{1-3}$. In the various studies, the gravity of cognitive involvement varies from a discreet impairment restricted to specific domains $s^{4,5}$ to severe dementia ${ }^{1,2,3,6}$. Recent studies have referred to mild cognitive impairment (MCI) in PD, as in other clinical conditions, this being clinically characterised as intermediary between normal cognition and dementia ${ }^{5}$.
The relationship between motor aspects and compromised cognition in PD is controversial ${ }^{7}$. Some studies suggest that dementia occurs in cases with rapid progression of the motor impairment or in those with prolonged cases of the disease $e^{4,5}$. Other studies suggest the occurrence of dementia in patients in which the motor manifestation is predominantly rigidity or rigidity/tremor ${ }^{1}$ or in those with axial motor compromise ${ }^{8}$. The relationship between aspects of cognitive compromise, such as its occurrence and gravity, and the age of the patient at the start of the disease and type of evolution, are also not yet clear.

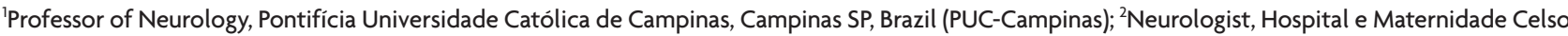
Pierro; ${ }^{3}$ Placement scholarship student PIBIC/CNPq, School of Medicine, PUC-Campinas; ${ }^{4}$ Neuropsychologist.
} 
The objective of the present study was to evaluate cognitive performance of PD patients in the standard neuropsychological battery of the Consortium to Establish a Registry for Alzheimer's Disease (CERAD), the Pfeffer questionnaire and the Clinical Dementia Rating (CDR) and correlate the results with clinical aspects, such as assessing the occurrence of dementia and mild cognitive impairment $(\mathrm{MCl})$ in this population.

\section{METHOD}

\section{Participants}

Thirty-two consecutive patients (16 female), with an average age of 67.2 (sd: 10.0 years), and with a probable or definitive clinical diagnosis of PD according to the criteria of Calne et al.', were included in this study. All were patients of the Neurology Clinic Outpatient's Department of the Celso Pierro Hospital and Maternity Hospital (PUC-Campinas, Brazil).

Information concerning the clinical data was obtained from an anamnesis with the patients and their relatives. All the patients included in the study took dopamine (mean dose - $292 \mathrm{mg}$; 150 to $500 \mathrm{mg}$ ), and were assessed in the on-phase. Patients using anti-psychotic or benzodiazepine medication were not included.

The Ethics Commission for Research with Human Beings of PUC-Campinas, approved the project, and the subjects signed an informed consent form.

\section{Procedures}

The procedures were: a clinical-neurological assessment; modified Hoehn-Yahr scale (HYS); standard neuropsychological battery of the Consortium to Establish a Registry for Alzheimer's Disease (CERAD); Pfeffer questionnaire; and Clinical Dementia Rating (CDR).

Motor disability was graded using the modified Hoehn and Yahr staging scale ${ }^{10}$.

The standard neuropsychological battery of CERAD, used in the cognitive assessment, was composed of a semantic verbal fluency assessment, abridged Boston Naming Test (15 items), the Mini-mental State Examination (MMSE), word list memory with repetition, recall and recognition, and constructional praxis with copy and recall ${ }^{11}$. Its applicability to the Brazilian population was certified ${ }^{12}$.

The Pfeffer questionnaire is a functional and cognitive assessment scale, applied to informants.

The validated Brazilian version of the $\mathrm{CDR}^{13,14}$ was used to determine the presence and gravity of dementia.

\section{Data analysis}

With respect to the motor aspects, the patients were classified according to the predomination of motor disability into 3 groups: (1) tremor, (2) rigidity or (3) tremor/rigidity.

With respect to the cognitive aspects, the group of PD patients was divided into 3 sub-groups based on the clinical-neurological assessment and the standardised instruments.
(1) Parkinson with normal cognition (PD-NLCog) - with no apparent cognitive impairment.

(2) Parkinson with mild cognitive impairment (PD-MCI) - corresponding to cognitive complaints coming from the patients or their families; the reporting of a relative decline in cognitive functioning during the past year by a patient or informant; cognitive disorders as evidenced by a clinical evaluation; absence of major repercussions on daily life; and absence of dementia ${ }^{15}$.

(3) Parkinson with dementia (PD-D) - dementia according to the Psychiatric Disease Diagnosis and Statistics Manual (DSMIV) ${ }^{16}$, starting at least one year after the installation of PD and without the characteristics of dementia with Lewy bodies.

The cognitive aspects were compared with those of a control group (CG) consisting of 26 individuals with no history of cognitive impairment or neuropsychiatric disability, and with similar ages and educational levels.

The relationship of the cognitive aspects with age, age when it started, duration, motor aspects of the PD and occurrence of depression were studied in the three sub-groups.

Parametric and non-parametric statistical analyses were used according to the situation under study, with a significance level of $\mathrm{p}<0.05$, using the SPSS, version 10.0 programme.

\section{RESULTS}

Thirty-two subjects (50\% female) with Parkinson's disease (PD group) and 26 subjects (65.4\% female) in the control group (CG), were studied.

According to the cognitive assessment, the distribution of the patients with PD in the 3 sub-groups was the following: (1) Parkinson with normal cognition (PD-NLCog) - with no apparent cognitive impairment - 15 cases; (2) Parkinson with mild cognitive impairment (PD-MCI) - 10 cases; and (3) Parkinson with dementia (PD-D) - 7 cases.

Table 1 shows the socio-demographic data and the clinical and cognitive aspects of the PD group and its sub-groups and of the CG group, as also the results in the comparisons.

There was no statistical difference between the PD and CG groups with respect to age and schooling level ( $T$ test, $p=0.55 ; p=0.08$ respectively), but there was a significant and positive correlation between schooling level and performance in all cognitive aspects studied (Spearman correlation, $\mathrm{p}<0.05$ )

The PD patients showed statistically significant inferior cognitive performance in all the items of the CERAD ( $p<0.05$ in the $T$ test or in the Mann-Whitney $U$ test).

\section{Clinical and cognitive aspects in the PD sub-groups}

A comparison was made between the PD sub-groups and the CG with respect to the socio-demographic, clinical and cognitive aspects using analysis of variance (ANOVA). Direct post hoc multiple comparisons between the PD subgroups and the CG (Duncan method) were subsequently made for the data showing significant differences (Table 1). 
Table 1. Socio-demographic, clinical and cognitive aspects in the total cases with Parkinson (PD) and in the Parkinson sub-groups with no cognitive alterations (PD-NLCog), with mild cognitive impairment (PD-MCI), with dementia (PD-D) and control (CG) in means (SD), as also the results of comparisons (PD $\times C G)$ and post hoc pairwise multiple comparisons.

\begin{tabular}{|c|c|c|c|c|c|c|c|c|}
\hline & \multirow[b]{2}{*}{$\begin{array}{l}P D \\
N=32\end{array}$} & \multirow[b]{2}{*}{$\begin{array}{l}C G \\
N=26\end{array}$} & \multirow[b]{2}{*}{$\begin{array}{l}\text { PD-NLCog } \\
\quad \mathrm{N}=15\end{array}$} & \multirow[b]{2}{*}{$\begin{array}{l}\text { PD-MCl } \\
\mathrm{N}=10\end{array}$} & \multirow[b]{2}{*}{$\begin{array}{l}\text { PD-D } \\
N=7\end{array}$} & \multirow[b]{2}{*}{$\begin{array}{l}P D \times C G \\
(p \text { value })\end{array}$} & \multicolumn{2}{|c|}{$\begin{array}{l}\text { Multiple comparisons (Duncan method) } \\
\text { after significant results in ANOVA }(p<0.05)\end{array}$} \\
\hline & & & & & & & $\begin{array}{l}\text { PD-NLCog } \\
\times \text { CG }\end{array}$ & $\begin{array}{c}\text { Other multiple } \\
\text { comparisons between } \\
\text { PD sub-groups and CG }(\mathrm{p}<0.05)\end{array}$ \\
\hline Age (years) & $67.2(10.0)$ & $68.4(4.7)$ & $63.6(9.6)$ & $70.3(10.2)$ & $70.6(9.1)$ & $0.551^{1}$ & * & * \\
\hline Duration of PD (years) & $7.0(4.9)$ & - & $6.8(3.9)$ & $6.0(2.4)$ & $8.7(8.6)$ & - & - & * \\
\hline Hoen \& Yahr scale & $2.1(0.7)$ & - & $1.9(0.7)$ & $2.0(0.6)$ & $2.6(0.4)$ & - & - & * \\
\hline Schooling level (years) & $3.9(4.3)$ & $6.1(5.0)$ & $5.9(5.4)$ & $2.3(1.6)$ & $1.7(2.4)$ & $0.085^{1}$ & NS & PD-D $\neq$ PD-NLCog and CG \\
\hline Verbal fluency & $12.3(4.2)$ & $16.2(4.7)$ & $14.7(3.1)$ & $11.6(3.0)$ & $8.1(4.2)$ & $0.002^{1}$ & NS & $\begin{array}{l}\text { groups differ except } \\
\text { PD-NLCog } \times \text { PD-MCI }\end{array}$ \\
\hline Word list recall & $3.6(2.6)$ & $5.8(1.9)$ & $5.8(1.7)$ & $1.9(1.4)$ & $1.3(0.5)$ & $0.000^{2}$ & NS & $\begin{array}{l}\text { groups differ except } \\
\text { PD-D } \times \text { PD-MCI }\end{array}$ \\
\hline Constructional praxis & $1.7(1.4)$ & $0.5(0.5)$ & $0.7(0.9)$ & $1.8(0.8)$ & $3.4(2.4)$ & $0.000^{2}$ & NS & $\begin{array}{l}\text { groups differ except } \\
\text { PD-D } \times \text { PD-MCI }\end{array}$ \\
\hline Word list recognition & $6.2(4.0)$ & $8.5(2.1)$ & $7.9(3.2)$ & $5.4(2.2)$ & $3.9(5.9)$ & $0.011^{1}$ & NS & $\begin{array}{l}\text { groups differ xcept } \\
\text { PD-D } \times \text { PD-MCI }\end{array}$ \\
\hline Constructional praxis recall & $2.4(1.6)$ & $1.6(1.5)$ & $1.5(1.1)$ & $2.8(1.3)$ & $3.7(1.9)$ & $0.04^{2}$ & NS & $\begin{array}{l}\text { groups differ except } \\
\text { PD-D } \times \text { PD-MCl }\end{array}$ \\
\hline Abridged Boston naming test & $11.2(2.5)$ & $13.3(1.6)$ & $13.1(1.8)$ & $10.4(0,3)$ & $8.4(2.3)$ & $0.001^{2}$ & NS & All groups differ \\
\hline Word list memory with repetition & $11.0(5.7)$ & $17.6(3.4)$ & $15.4(3.4)$ & $9.1(4.7)$ & $4.4(2.4)$ & $0.000^{1}$ & NS & All groups differ \\
\hline Mini-mental State Examination & $22.3(6.1)$ & $26.6(2.2)$ & $26.8(2.7)$ & $22.1(2.8)$ & $12.9(3.3)$ & $0.001^{1}$ & NS & All groups differ \\
\hline Pfeffer Scale & $0.7(0.9)$ & $0.0(0.0)$ & $0.1(0.2)$ & $0.4(0.3)$ & $2.1(0.3)$ & $0.000^{2}$ & NS & All groups differ \\
\hline
\end{tabular}

SD: standard deviation; 'T test; ${ }^{2}$ Mann-Whitney test; *ANOVA not significant; NS: not significant (Duncan method after ANOVA).

There was no statistically significant difference between the PD sub-groups and CG with respect to age (ANOVA, $p=0.15)$, duration of PD $(p=0.54)$ and Hoen \& Yahr scale (0.06) (Table 1). A comparison was made between patients with PD with and without dementia, and higher values in Hoen \& Yahr scale were observed in PD-D group (Mann-Whitney U test, $\mathrm{p}=0.023$ ).

The patients with PD-D showed a lower schooling level than the PD-NLCog and CG groups (Table 1).

In the standard neuropsychological battery of CERAD, there was no significant difference between the PD-NLCog sub-group and the CG. The patients with PD-D and with $\mathrm{PD}-\mathrm{MCl}$ showed significantly inferior performance in all the trials, when compared with the PD-NLCog sub-group and CG (Table 1).

There was a significant difference between PD-MCI and PD-D groups in abridged Boston Naming Test, Minimental State Examination, Pfeffer Scale, word list memory with repetition and Clinical Dementia Rating, when compared to PD-MCl.

\section{Relationship between the motor} capacity and cognitive aspects

With respect to the classification of the PD patients into 3 groups according to whether the predominant mo- tor manifestation was trembling, rigidity or trembling/rigidity (Table 2), there was a significant difference between the groups in the standard neuropsychological battery of CERAD in the following tests: word list recall, constructional praxis and MMSE (ANOVA, $p<0.05$ ). The post hoc pairwise comparisons (Duncan method) showed inferior performances for the group "trembling/rigidity" when compared with de group "rigidity".

In the study of correlation between motor compromise (modified HYS) and cognitive aspects, there were not significant correlations (Pearson, $\mathrm{p}>0.05$ ).

\section{DISCUSSION}

\section{Clinical aspects and cognitive decline}

The present casuistic is composed of patients with idiopathic PD, with a mean age of 67 years, low mean schooling level and a mean score in the modified HYS of 2.1.

Although age, time of disease and even a greater age at the start of the PD have been indicated in the literature as risk factors for the occurrence of cognitive impairment ${ }^{2,4}$, in agreement with other authors ${ }^{17,18}$, no such relationship was found in the present study.

It was observed that a higher schooling level was associated with a reduced risk in cognitive impairment, confirming earlier studies with PD patients ${ }^{6,19}$. Nevertheless 
Table 2. Mean scores and standard deviations for PD patients in the CERAD battery, according to the predominant motor manifestation and the $p$ value in the Kruskal Wallis test.

\begin{tabular}{|c|c|c|c|c|c|c|c|}
\hline & \multicolumn{2}{|c|}{$\begin{array}{l}\text { Trembling } \\
\qquad \mathrm{N}=9\end{array}$} & \multicolumn{2}{|c|}{$\begin{array}{l}\text { Rigidity } \\
\mathrm{N}=5\end{array}$} & \multicolumn{2}{|c|}{$\begin{array}{l}\text { Trembling/Rigidity } \\
\text { N=18 }\end{array}$} & \multirow[b]{2}{*}{$\mathrm{p}$} \\
\hline & mean & SD & mean & SD & mean & SD & \\
\hline Word list memory with repetition & 12.6 & 6.3 & 16.2 & 2.5 & 8.8 & 5.1 & $0.020 *$ \\
\hline Constructional praxis & 1.1 & 1.5 & 0.5 & 0.5 & 2.3 & 1.1 & $0.006^{*}$ \\
\hline MMSE (total) & 24.7 & 6.4 & 26.8 & 1.6 & 19.8 & 5.8 & $0.020^{*}$ \\
\hline
\end{tabular}

SD: standard deviation; *significant values in ANOVA $p<0.05$.

longitudinal studies are required to elucidate the aspect of the "protective effect" of a higher level of formal education on the cognition of PD patients" 19 .

The lower schooling level and greater gravity of the motor compromise according to the modified HYS were the factors contributing to the occurrence of cognitive deficits in patients with PD. The association between gravity of motor compromise and cognitive impairment has been indicated in the majority of publications $s^{1,2,3,6,18,20}$, although there is a lack of unanimity on the subject ${ }^{4}$.

With respect to the type of motor compromise, greater cognitive compromise is not observed in patients with predominant rigidity as compared to trembling, as reported in some studies ${ }^{1,3}$. The association between the predominant type of motor manifestation and cognitive involvement is controversial: while some authors suggest an intricate relationship between the motor symptoms, the course of the disease and the extent of cognitive deterioration ${ }^{7}$, others refer to a possible relationship between a fluctuation of the signals/motor symptoms and cognitive involvement ${ }^{21}$.

The compromise in functional activities observed in PD patients in the assessment with the Pfeffer questionnaire and CDR, despite being assessed in the on phase, could, in part, be related to motor disability in addition to being related to cognitive compromise ${ }^{2,3}$.

\section{Specific cognitive domains}

The inferior results in semantic verbal fluency in the patients in sub-groups PD-D and PD-MCl as compared to those in the PD-NLCog or CG groups, suggests involvement of specific cognitive domains such as executive and memory functions similar to other reports found in the literature ${ }^{22,23}$. Compromised verbal fluency is very common in PD and could represent a predictive factor for the development of dementia ${ }^{24}$.

The inferior performance in the praxis trials could be a result of the motor disorder, characteristic of these patients, as much as being a failure in the planning and sequential control of their movements. Thus this finding could suggest that the visual-constructive abilities of the patients assessed in this study could have been affected to a certain extent by an executive disorder ${ }^{25}$.

The memory difficulty expressed in their recall deficit of the word list in this study, reveals one of the domains most affected in PD, and is attributed to an executive disorder caused by a slowing-up of the information process or by impairment in evocative strategies more than a mnemic deficit as such.. Thus the memory difficulties shown by PD patients could reflect the involvement of multiple cortical and sub-cortical neural pathways and not temporal-limbic involvement ${ }^{2,26}$.

These mechanisms could also be responsible for the difficulties shown in the word list memory with repetition task, as found in this study.

\section{Dementia and mild cognitive impairment in PD}

The finding of $21.8 \%$ dementia in the cases assessed in this study is in agreement with the values from $17.68 \%$ to $41.3 \%$ reported in community studies that used the criteria of the Diagnostic and Statistical Manual of Mental Disorders (DSM)-IIIR to characterise dementia ${ }^{16,17,27,28}$.

An association was found between the occurrence of dementia and greater gravity of the motor compromise as assessed by the modified HYS.

Various references can be found in the literature with respect to a relationship between dementia and the score obtained on the Unified Parkinson Disease Rating Scale, especially in the sub-score indicating predominantly dopaminergic dysfunction ${ }^{6,8}$.

The pathophysiology of dementia in PD appears to be of a multifactor nature, encompassing sub-cortical and cortical neuronal populations ${ }^{26}$.

Studies on the occurrence of $\mathrm{MCl}$ are still rare, and the finding of $31.2 \%$ of the patients in the present study is similar to the rate found by Caviness et al. ${ }^{29}$ of $24.3 \%$ of the cases. Few longitudinal studies have been carried out, but according to Janvin et al. ${ }^{5}$, the presence of $\mathrm{MCl}$ in PD, as also in the population at large $\mathrm{e}^{30}$, is associated with a greater risk of developing dementia.

Although it is known that some patients with PD remain relatively intact from the cognitive point of view, 
the recognition of $\mathrm{MCl}$ in PD patients during the course of the disease ${ }^{7}$ is of great importance, since it allows one to foresee a greater risk of the implantation of dementia.

In summary, it could be observed in the present study that cognitive compromise appeared in a significant percentage of PD patients, expressed not only as dementia but also as mild cognitive impairment. Schooling level and motor compromise were factors connected to the existence of these cognitive deficits. The characterisation of cognitive involvement and its gravity in PD is of great clinical importance, since it can be of use in better orientation of the patients and the introduction of therapeutic strategies.

\section{REFERENCES}

1. Aarsland D, Andersen K, Larsen JP, Lolk A, Kragh-Soremsen P. Prevalence and characteristics of dementia in Parkinson's disease: an 8-year prospective study. Arch Neurol 2003;60:387-392.

2. Emre M. Dementia associated with Parkinson's disease. Lancet Neurol 2003;2:229-237.

3. Verbaan D, Marinus J, Visser M, et al. Cognitive impairment in Parkinson' disease. J Neurol Neurosurg Psychiatry 2007;78:1182-1187.

4. Muslimovic D, Post B, Speelman JD, Schmand B. Cognitive profile of patients with newly diagnosed Parkinson's disease. Neurology 2005;65:1239-1245.

5. Janvin CC, Larsen JP, Aarsland D, Hugdahl K. Subtypes of mild cognitive impairment in Parkinson's disease: progression to dementia. Mov Disord 2006;9:1343-1349.

6. Levy G, Jacobs DM, Tang MX. Memory and executive function impairment predict dementia in Parkinson disease. Mov Disord 2002;17:1221-1226.

7. Katzen HL, Levin BE, Weiner W. Side and type of motor symptom influence cognition in Parkinson's disease. Mov Disord 2006;21:1947-1953.

8. Levy G, Tang MX, Cote LJ, et al. Motor impairment in PD: relationship to incident dementia and age. Neurology 2000;55:201-206.

9. Calne DB, Snow BJ, Lee C. Criteria for diagnosing Parkinson's disease. Ann Neurol 1992;32(Suppl):S125-S127.

10. Goetz CG, Poewe W, Rascol O, et al. Movement Disorder Society Task Force Report on the Hoehn and Yahr Staging Scale: status and recommendations. Mov Disord 2004;19:1020-1028.

11. Morris JC, Heyman A, Mohs RC. The Consortium to establish a registry for Alzheimer's disease (CERAD): part 1. Clinical and neuropsychological assessment of Alzheimer's disease. Neurology 1989;39:1159-1165.

12. Bertolucci PHF, Okamoto IH, Brucki SMD, Siviero MO, Toniolo Neto J, Ramos LR. Applicability of the CERAD neuropsychological battery to Brazilian elderly. Arq Neuropsiquiatr 2001;59:532-536.

13. Morris JC. The clinical dementia rating (CDR): current version and scoring rules. Neurology 1993;43:2412-2414.

14. Maia ALG, Godinho C, Ferreira ED, et al. Application of the
Brazilian version of the CDR scale in samples of dementia patients. Arq Neuropsiquiatr 2006;64:485-489.

15. Portet F, Ousset PJ, Visser PJ, et al. Mild cognitive impairment (MCI) in medical practice: a critical review of the concept and new diagnostic procedure. Report of the $\mathrm{MCI}$ working group of the European consortium of Alzheimer's disease. J Neurol Neurosurg Psychiatry 2006;77:714-718.

16. American Psychiatric Association. Diagnostic and statistical manual of mental disorders. $3^{\text {rd }}$ ed. Washington, DC. American Psychiatric Association, 1994.

17. Marder K, Tang MX, Cote L. The frequency and associated risk factors for dementia in patients with Parkinson's disease. Arch Neurol 1995;52:695-701.

18. Hughes TA, Ross HS, Musa S, et al. A 10-year study of the incidence of and factors predicting dementia in Parkinson's disease. Neurology 2000;54:1596-1602.

19. Cohen OS, Vakil E, Tanne D, Nitsan Z, Schwartz R, HassinBaer S. Educational level as a modulator of cognitive performance and neuropsychiatry features in Parkinson disease. Cogn Behav Neurol 2007;20:68-72.

20. Fuchs GA, Gemende J, Herting B, et al. Dementia in idiopathic Parkinson's disease. J Neurol 2004;251:28-32.

21. Bodis-Wollner I. Neuropsychological and perceptual defects in Parkinson's disease. Parkinsonism Relat Disord 2003;9:83-89.

22. Gurd JM, Ward CD. Retrieval from semantic and letter-initial categories in patients with Parkinson's disease. Neuropsychologia 1989;27:743-746.

23. Raskin SA, Sliwinski M, Borod JC. Clustering strategies on tasks of verbal fluency in Parkinson's disease. Neuropsychologia 1992;30:95-99.

24. Mahieux F, Fenelon G, Flahault A, Manifacier MJ, Michelet D. Neuropsychological prediction of dementia in Parkinson disease. J Neurol Neurosurg Psychiatry 1998;64:178-183.

25. Stern Y, Mayeux R, Rosen J, et al. Perceptual motor dysfunction in Parkinson's disease: a deficit in sequential and predictive voluntary movement. J Neurol Neurosurg Psychiatry 1983;46:145-151

26. Rippon GA, Marder KS. Dementia in Parkinson's disease Advances in Neurology 2005;96:95-113.

27. Ebmeier KP, Calder SA, Crawford JR, et al. A population-based investigation of Parkinson's disease with and without dementia: relationship to age and gender. Arch Neurol 1992;45:705-708

28. Aarsland D, Tandberg E, Larsen JP, Cummings JL. Frequency of dementia in Parkinson disease. Arch Neurol 1996;53: 538-542.

29. Caviness JN, Hentz JG, Evidente VG, et al. Both early and late cognitive dysfunction affects the electroencephalogram in Parkinson's disease. Parkinsonism Related Disord 2007;13:348-354.

30. Petersen RC, Smith GE, Waring SC, et al. Mild cognitive impairment: clinical characterization and outcome. Arch Neurol 1999;56:303-308. 